\title{
Problems of and Reflections on Task Design in Graduate English Textbooks
}

\author{
Wang Zhen \\ Foreign Language Department, Qingdao Agricultural University, Qingdao, Shandong Province, China \\ wangjiazhenhope@163.com
}

\begin{abstract}
This survey aims to find the problems of task design in graduate English textbooks. 630 directions of tasks are collected from two textbooks. The analysis shows that the main problems are as follows: first, design concept are based on language knowledge to ignore language application ability; second, design objective stresses language forms more than language meanings; third, design contents stress language knowledge more than humanistic quality; forth, design goal stress individual-skill tasks more than integrated ones, fifth, present forms of tasks are simple, mainly words without the use of pictures, audio and video materials.
\end{abstract}

Index Terms - Graduate English textbooks, Task design, Problems, Reflection

\section{Introduction}

Jolly \& Bolitho [1] and Tomlinson [2] think that the task design after texts in the textbooks is an important aspect of textbook construction, which embodies the editor's compilation conceptions, guides and standardizes teaching and learning, so, to some extent it is more important than article selection in textbooks [3]. The main purpose of this research is to examine whether the task design is beneficial to cultivate and improve graduate students' comprehensive English application ability, communicative ability, practice and innovation ability, and critical thinking ability.

\section{Research Design}

\section{A. Sample Collection}

This survey chose Integrated Course (Shorted as IC, 1st and 2nd Vol. Xiong Haihong as editor-in-chief, Foreign Language Teaching and Research Press, Beijing) and Comprehensive English (Shorted as CE. Qiu Donglin as editor-in-chief, Shanghai Foreign Language Education Press, Shanghai) as the graduate English textbook samples. A total of 630 task instructions are collected from textbooks(refer with: table 1). It needs to be pointed out that a few steps to complete a whole task are marked as a task instruction.

TABLE 1 Numbers of Task Instructions in Textbooks

\begin{tabular}{|c|c|c|c|c|c|c|c|c|c|c|}
\hline \multirow{2}{*}{ TB } & \multicolumn{10}{|c|}{ Units } \\
\cline { 2 - 12 } & $\mathrm{U}$ & $\mathrm{U}$ & $\mathrm{U}$ & $\mathrm{U}$ & $\mathrm{U}$ & $\mathrm{U}$ & $\mathrm{U}$ & $\mathrm{U}$ & $\mathrm{U}$ & $\mathrm{U}$ \\
& 1 & 2 & 3 & 4 & 5 & 6 & 7 & 8 & 9 & 10 \\
\hline IC1 & 19 & 17 & 18 & 19 & 18 & 18 & 19 & 20 & 18 & 18 \\
\hline IC2 & 18 & 18 & 17 & 20 & 20 & 19 & 18 & 18 & 19 & 18 \\
\hline $\mathrm{CE}$ & 32 & 39 & 32 & 32 & 32 & 32 & 31 & 31 & $/$ & $/$ \\
\hline
\end{tabular}

(TB stands for textbooks)

\section{B. Data Collection}

1) Communicative/Non-communicative Tasks: The survey divides the tasks into communicative and non-communicative tasks. The distribution of communicative/non-communicative tasks in two textbooks refer with fig. 1 and fig.2. Two volumes of Integrated Course are regarded as one textbook for the convenient statistical analysis, fig.3, fig.5 and fig. 7 use the same statistical method, no longer another note.

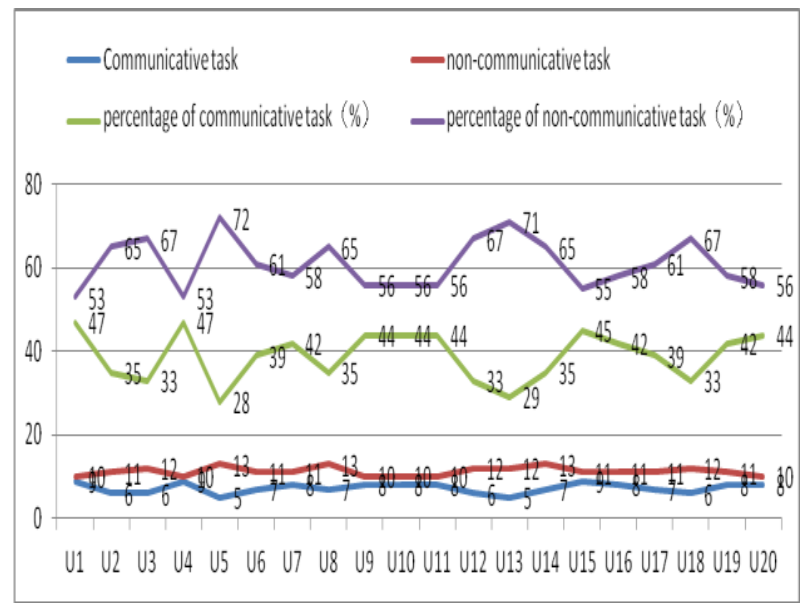

Fig. 1 Integrated Course

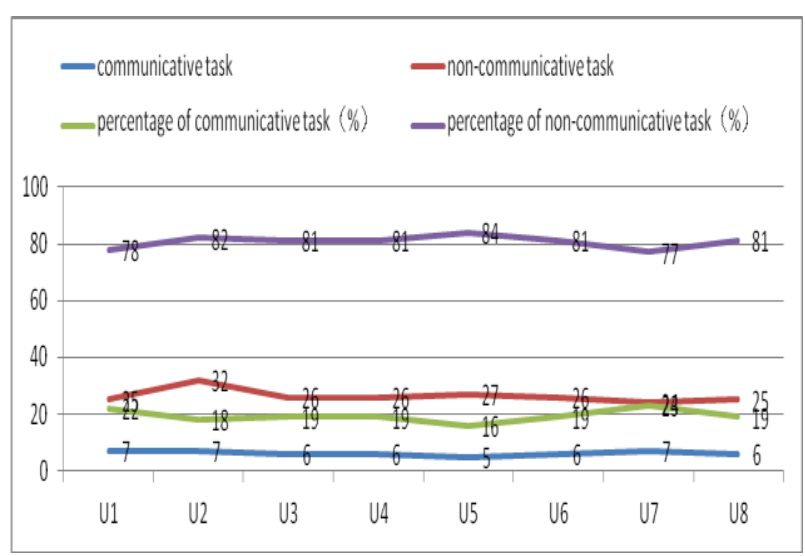

Fig. 2 Comprehensive English

2) Individual/Integrating-skill Tasks: The investigation of distribution of individual/integrating-skill tasks is to examine whether the task design in textbooks contribute to students'English comprehensive application ability. A task 
instruction with two or more skills is marked as an integrating-skill task. The distribution can refer with fig. 3 and fig. 4 .

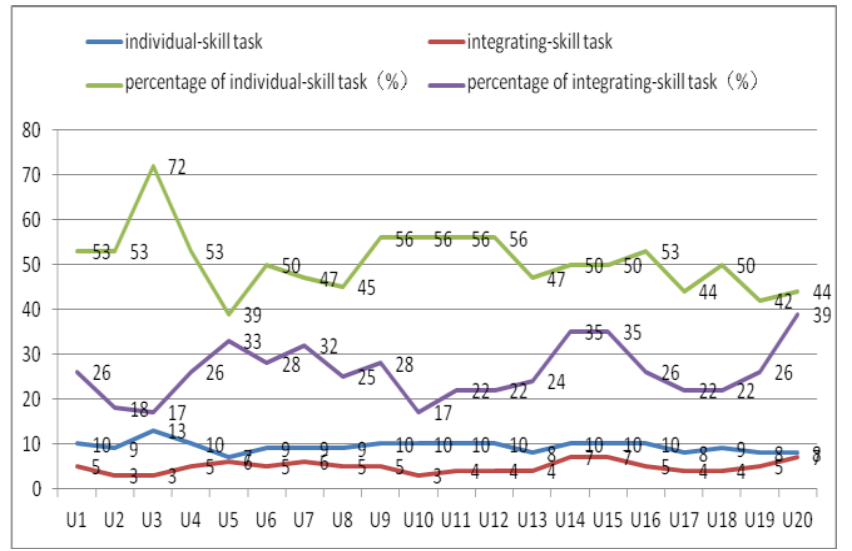

Fig. 3 Integrated Course

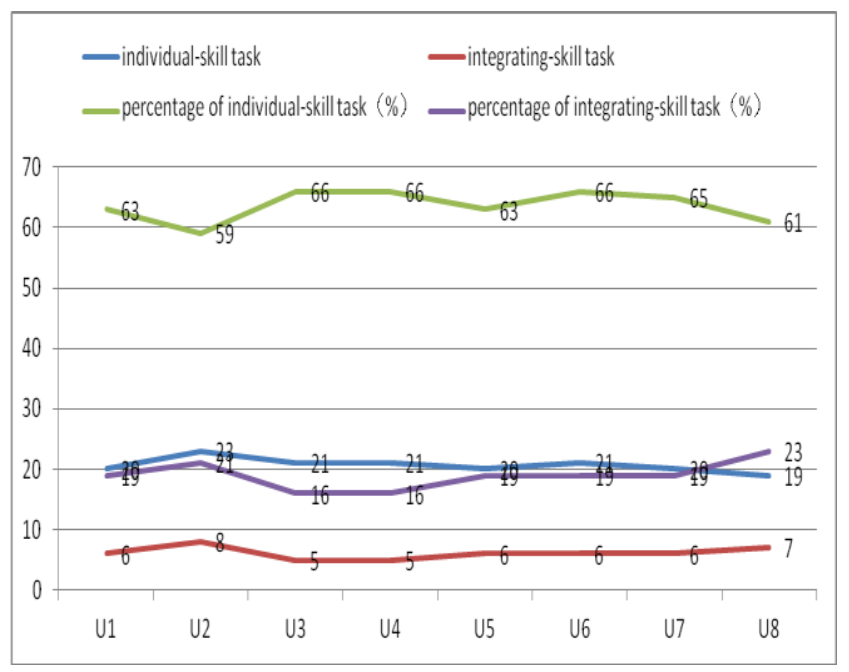

Fig. 4 Comprehensive English

3) Open/Closed Tasks: From the outcomes of the task completion, the exercises and activities after the texts in textbooks are divided into open and closed tasks. The distribution in two textbooks is shown in fig. 5 and fig. 6.

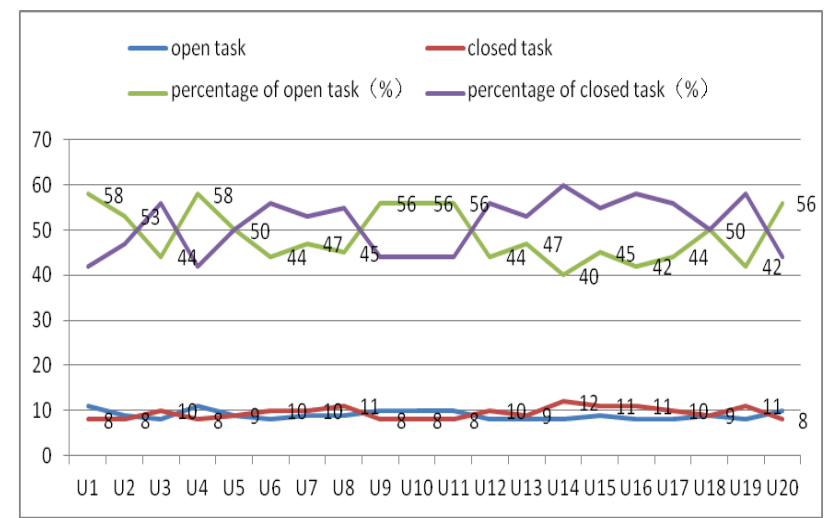

Fig. 5 Integrated Course

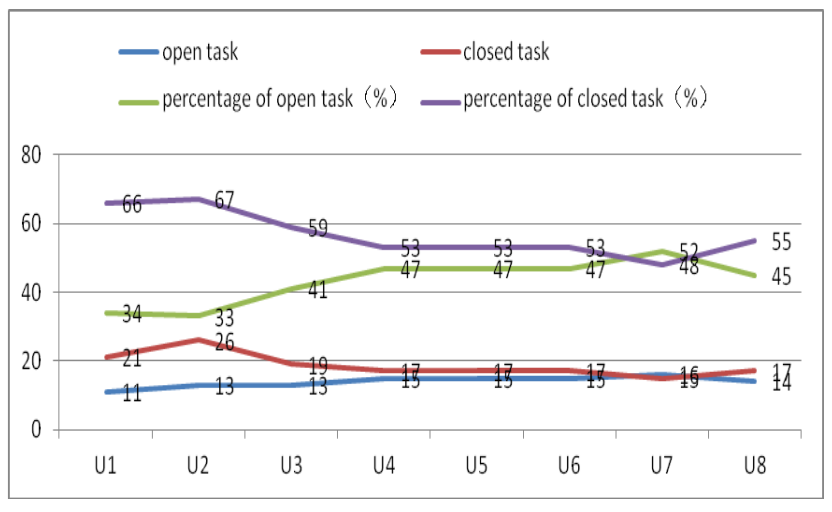

Fig. 6 Comprehensive English

4) Single/Multi Task: According to whether the tasks need one or many students (including two) to complete, the tasks are divided into single and multi task. The distribution in two textbooks refers with fig. 7 and fig. 8.

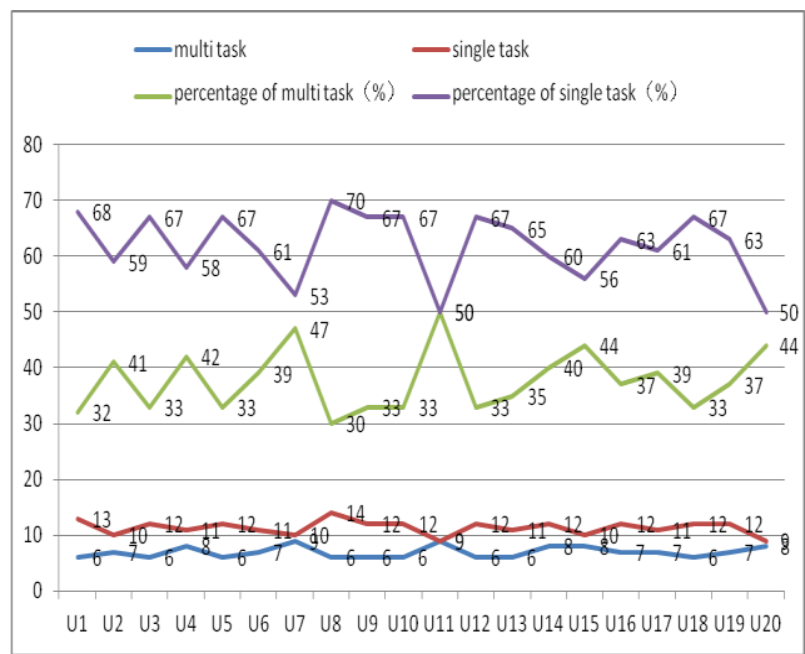

Fig.7 Integrated Course

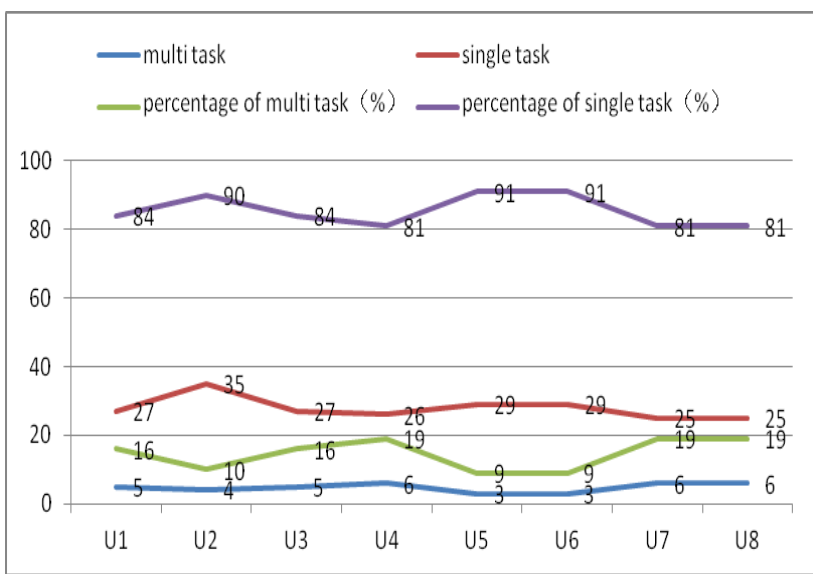

Fig. 8 Comprehensive English

5) Distribution of Presenting Forms of Tasks: The presenting forms of task refer that the task content is presented with the written-word instructions or picture, audio, 
video etc. multimodal forms, which are collectively referred to as non-written forms. Listening exercises are excluded in this survey. The distribution of presenting forms refers with table 2 .

TABLE 2 Presenting Forms of Task in Textbooks

\begin{tabular}{|c|c|c|c|c|c|c|}
\hline \multirow{2}{*}{$\mathrm{U}$} & \multicolumn{2}{|c|}{$\mathrm{IC} 1$} & \multicolumn{2}{c|}{ IC2 } & \multicolumn{2}{c|}{$\mathrm{CE}$} \\
\cline { 2 - 7 } & $\mathrm{N}-\mathrm{W}$ & $\mathrm{F}$ & $\mathrm{N}-\mathrm{W}$ & $\mathrm{F}$ & $\mathrm{N}-\mathrm{W}$ & $\mathrm{F}$ \\
\hline $\mathrm{U} 1$ & 1 & picture & 0 & $/$ & 0 & $/$ \\
\hline $\mathrm{U} 2$ & 0 & $/$ & 1 & cartoon & 0 & $/$ \\
\hline $\mathrm{U} 3$ & 1 & graphic & 0 & $/$ & 0 & $/$ \\
\hline $\mathrm{U} 4$ & 0 & $/$ & 0 & $/$ & 0 & $/$ \\
\hline U5 & 0 & $/$ & 0 & $/$ & 0 & $/$ \\
\hline U6 & 2 & picture & 0 & $/$ & 0 & $/$ \\
\hline U7 & 0 & $/$ & 0 & $/$ & 0 & $/$ \\
\hline U8 & 1 & picture & 1 & picture & 0 & $/$ \\
\hline U9 & 0 & $/$ & 0 & $/$ & $/$ & $/$ \\
\hline U10 & 0 & $/$ & 1 & cartoon & $/$ & $/$ \\
\hline Total & 5 & $/$ & 3 & $/$ & 0 & $/$ \\
\hline$\%$ & 2.72 & $/$ & 1.62 & $/$ & 0 & $/$ \\
\hline
\end{tabular}

(N-W stands for non-written forms, F stands for forms.)

\section{Results}

1) Non-communicative Tasks More Than Communicative Tasks: Figure 1 and figure 2 show that the proportion of communicative tasks is significantly lower than that of non-communicative tasks in graduate English textbooks. The highest proportion of the non-communicative task of each unit is $72 \%$ in Integrated Course, and the proportion in Comprehensive English is near to $80 \%$, the highest is $84 \%$.

2) Individual-skill Tasks More Than Integrating-skill Task: Fig.3 and fig.4 show that the proportion of individual-skill task is significantly higher than that of integrating-skill task in two textbooks. The highest proportion of individual-skill task of each unit is $72 \%$ in Integrated Course and all proportions are almost above $60 \%$ in comprehensive English.

3) Closed Tasks More Than Open Tasks: Fig. 5 shows that the proportion of closed and open tasks is almost the same in Integrated Course 1 (U1-U10), but the proportion of closed tasks is obviously higher than that of open tasks in Integrated Course 2 (U11-U20). Fig. 6 shows that the proportion of closed tasks declines in Comprehensive English, from $66 \%$ of unit 1 to $55 \%$ of unit 8 , but overall, the proportion of the closed task is still higher than that of open tasks.

4) Single tasks more than multi tasks: Figure 7 shows that the proportion of single task of each unit is basically higher than $50 \%$, with the proportion of unit 16 higher than $60 \%$, in Integrated Course. Figure 8 shows that the proportion of single task of each unit all is higher than that of multi tasks in Comprehensive English, all higher than $80 \%$.
5) Tasks Mainly Presented in Written Forms, Individual with Pictures: The data in table 2 show that the tasks are mainly presented in written forms and fewer in non-written forms in two textbooks. There are just 5 tasks presented in non-written forms in Integrated Course 1, 2.72\% (5/184) of total task number. However, there are only 3 tasks in non-written forms in Integrated Course2 1.62\% (3/185). However, the tasks are presented only in written forms in Comprehensive English.

\section{Discussion}

\section{A. Task Design Concept Based on Language Knowledge Not} Language Application Ability

More non-communicative and closed tasks mainly beat into students" heads the "usage" of the language knowledge rather than the "use" (refer with:fig 5 and fig. 6, fig. 1 and fig.2), and the closed tasks basically have the fixed answers. Although it is beneficial for learners to learn language knowledge to some extent, which hinders the cultivation of students' communicative ability. And the single tasks are more than multi tasks in two textbooks (refer with:fig. 7 and fig. 8). The single task design mainly encourages students to complete the task alone, which is not conducive to student interaction, communication, cooperation and negotiation.

\section{B. Tasks Designed on Language Form Not Meaning}

The tasks types in textbooks are mainly closed tasks from the perspective of the outcome of task completion (refer with: fig. 5 and fig. 6). A lot of controlled exercises in the textbooks regard the language as a series of "products" to teach, but second language acquisition studies have shown that learners do not acquire language in this way [4]. Task teaching method advocates language acquisition through the real tasks [5]. Textbook writers need to consider how to design the communicative tasks in order to increase its proportion and to give students a large number of opportunities to communicate language meaning.

\section{Task Content Belittle Humanistic Quality}

As mentioned earlier, the task contents give priority to language knowledge and form, with exercise for exercise, neglecting the cultivation of students' positive humanistic quality in the emotional and cognitive aspects.

Humanistic principle of humanistic language teaching emphasizes that students' comprehensive potential growth can be acquired through the recognition of the importance of emotional and cognitive categories in the learning success [4]. Therefore, the task designers of textbooks should actively explore effective task forms to help students form right world outlooks, life outlooks and values in the process of language learning.

\section{Task Goal Value Individual Skill Not Integrating Skills}

The proportion of the individual-skill task in textbooks is significantly higher than that of integrating-skill task (see fig.3 and fig.4). However, in real life language users often need to use both listening, speaking, reading, writing, translating etc. several skills to accept and transmit information. McDonough, Shaw \& Masuhara [6] think that 
treating skills discretely can cause the attention to language output accuracy and grammatical features. More useful, we can group the audio/oral skill of listening and speaking and "paper skills" of reading and writing. In this way the giver and receiver of information form an integral part of communication.

\section{E. Presenting Form of Task Is Simple, Mainly in Written Forms}

The presenting form of tasks in graduate English textbooks is mainly in written forms (refer with: table 2), which is dull, lack of originality, far behind the three-dimensional development trend of textbooks compiling. The three-dimensional textbooks make use of language media such as pictures, audio, video, and written forms. This makes presenting forms of tasks vivid, so it is conducive to meet students' diverse learning needs, realize students' personalized learning, and improve the students' interest in learning English. So textbook writers can put the audio and video materials into textbooks through network courseware and multimedia courseware of textbooksor by connecting textbooks to URL.

\section{Conclusions}

Based on the current main problems discussed above, the future task design needs to pay attention to five aspects. First, task design concept should be based on language application ability not on language knowledge. Second, the aim of task design should focus on language meaning rather than form. Third, the content of task design needs to combine knowledge and humanistic quality cultivation. Fourth, the goal of task design should be cultivation of the comprehensive skills. Fifth, the presenting forms of task should be three-dimensional.

\section{Acknowledgment}

This research was financially supported by the Social Science Foundation of Qingdao Agricultural University (Grant NO. 3Y47).

\section{References}

[1] Jolly, D. \& Bolitho, R. A framework for materials writing. In B. Tomlinson (Ed.), Materials Development in Language Teaching (2nd edition). Cambridge: Cambridge University Press. 2011, pp.107-134.

[2] Tomlinson, B. (Ed.). Introduction: principles and procedures of materials development. In B. Tomlinson (Ed.), Materials development in language teaching (2nd edition). Cambridge: Cambridge University Press. 2011, pp.1-34.

[3] Hua Weifen. Study of Task Design in Comprehensive English Textbooks for English Majors in China Colleges. Shanghai Foreign Language University, 2010.

[4] Ellis, R. Task-based Language Learning and Teaching. Shanghai: Shanghai Foreign Language Education Press, 2013, pp. 9-10, $29,31$.

[5] Samuda, V. \& Bygate, M. Tasks in Second Language Learning. Beijing: Foreign Language Teaching and Research Press, 2010, pp.7 to 17, 51-61.

[6] McDonough, J. Shaw, C. \& Masuhara, H. Materials and Methods in ELT-A Teacher's Guide, $3^{\text {rd }}$ ed. John Wiley \& Sons, Inc. 2013, pp.30. 